\title{
CONSUMER RESOURCE MATCHING IN URBANIZING LANDSCAPES: ARE SYNANTHROPIC SPECIES OVER-MATCHING?
}

\author{
Amanda D. Rodewald ${ }^{1}$ and Daniel P. Shustack \\ School of Environment and Natural Resources, Ohio State University, 2021 Coffey Road, Columbus, Ohio 43210 USA
}

\begin{abstract}
Population responses of synanthropic species to urbanization may be explained by the resource-matching rule, which postulates that individuals should distribute themselves according to resource availability. According to the resource-matching rule, urban habitats will contain greater densities if they provide better resources than rural habitats. However, because resource availability is density dependent, individuals in urban areas would ultimately achieve fitness levels comparable to, but no better than, individuals in less urban areas. Some ecologists suggest that synanthropic birds may not conform to the resource-matching rule and may instead overmatch (i.e., overexploit) in urban habitats, ultimately leading to lower fitness despite greater resource levels. Using the Northern Cardinal (Cardinalis cardinalis) as a focal species, we evaluated if Cardinal populations in urban and rural habitats were consistent with predictions of consumer resource matching. During 2003-2006 we documented population density, adult body condition, apparent survival, and annual reproductive productivity of Cardinals in riparian forest stands within urban ( $n=8$ stands) and rural ( $n=6$ stands) landscapes in Ohio, USA. Density of Cardinals in urban forests was four times that found in more rural forests. Mark-resight data from 147 males and 125 females over four years indicated that apparent survival rates were similar between urban and rural landscapes $(\phi=$ $0.64, \mathrm{SE}=0.039$ for males and $\phi=0.57, \mathrm{SE}=0.04$ for females). Similarly, body condition indices of 168 males, 142 females, and 118 nestlings did not differ significantly between landscapes. Annual reproductive productivity (mean number of fledglings per pair over breeding season) of 294 pairs was comparable for urban $(2.4 \pm 0.18$ [mean \pm SE] and rural $(2.1 \pm 0.18)$ young birds. Thus, contrary to recent suggestions, we find that high densities of certain synanthropic species in urban landscapes are consistent with expectations of consumer resource matching.
\end{abstract}

Key words: Cardinalis cardinalis; condition; consumer resource matching; ideal free distribution; Northern Cardinal; reproductive productivity; predation; survival; urban habitats.

\section{INTRODUCTION}

One of the most common patterns to emerge from ecological studies in urban systems is that urban environments are often dominated by a few species. Indeed, many urban tits, pigeons, doves, sparrows, thrushes, gulls, and corvids respond positively to urbanization across multiple continents (Marzluff et al. 2001). These synanthropic species usually reach much higher densities in urban than relatively more natural landscapes. Both bottom-up (e.g., improved food resources) and top-down (e.g., relaxed predation) factors have been suggested as potential mechanisms of population responses to urbanization (Faeth et al. 2005, Shochat et al. 2006), but studies have failed to identify which factors are most important in urban systems.

Population responses of avian synanthropes may reflect resource matching by consumers, whereby individuals distribute themselves according to resource

Manuscript received 2 March 2007; revised 23 May 2007; accepted 29 May 2007. Corresponding Editor: J. M. Marzluff.

${ }^{1}$ E-mail: rodewald1@osu.edu availability and distribution (Parker 1978, Pulliam and Caraco 1984, Shochat 2004). Assuming that individuals are distributed in an ideal-free manner (Fretwell and Lucas 1969), and that population density varies directly with resource availability, then the resource-matching hypothesis predicts that individual fitness should be comparable among patches or habitats. Nevertheless, some populations deviate from resource matching, and densities reflect either under-matching (i.e., underexploiting rich habitats; Kennedy and Gray 1993) or overmatching (i.e., overexploiting rich habitats; Shochat 2004), which can manifest itself in differences in condition and reproductive success among habitats.

Urban ecologists have recently proposed that some synanthropic species may over-match urban habitats (Shochat 2004, Faeth et al. 2005, Shochat et al. 2006). Thus, even in cases where urban habitats contain richer and more productive food resources for synanthropic species than rural habitats (Mills et al. 1989, Atchison and Rodewald 2006, Leston and Rodewald 2006), individual foragers would have access to comparatively fewer resources because densities exceed those predicted under the resource-matching rule. Shochat (2004) likened these urban populations to groups of few 

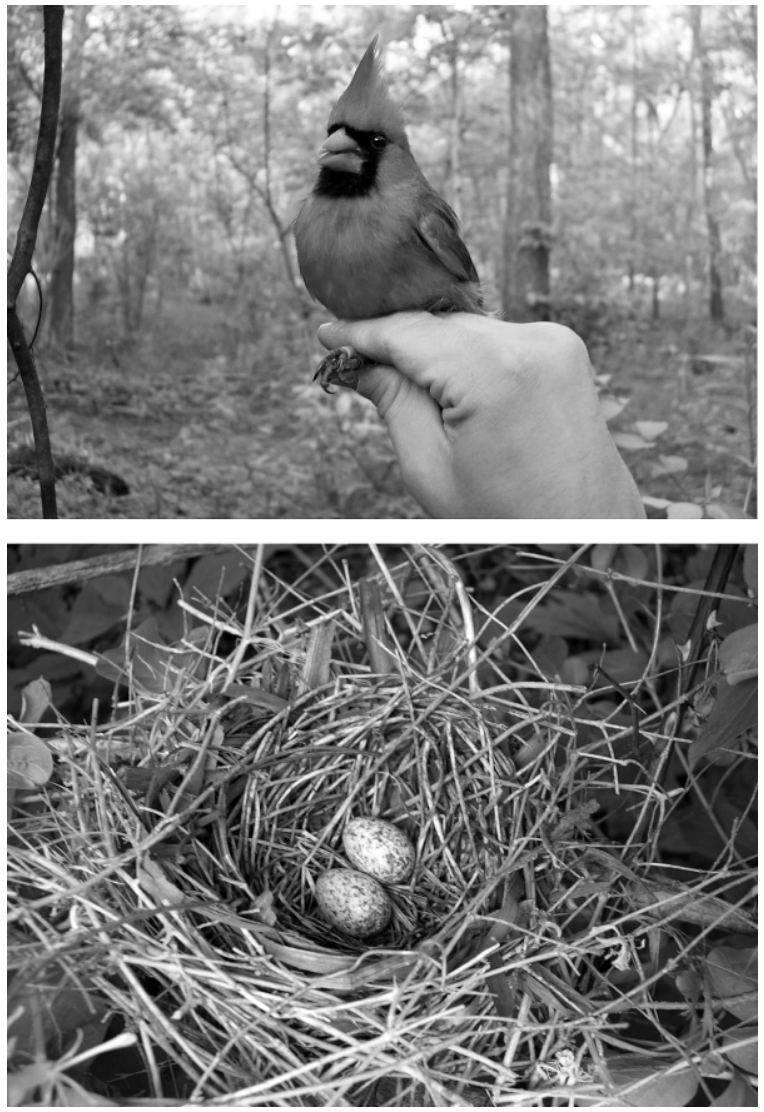

Plate 1. Riparian forests in urban landscapes support up to four times greater densities of Northern Cardinals (top) than forests in rural landscapes. Availability of nesting substrates (bottom) is one of several resources used by Cardinals that is positively associated with urbanization. Photo credits: D. Shustack.

"winners" (i.e., competitively dominant individuals who can secure ample resources) and many "losers" (i.e., most individuals who have low per capita resources due to the over-matching) in terms of condition, survival, and reproduction. However, no studies have explicitly tested this hypothesis.

In this paper we evaluate the resource-matching rule using a focal species, the Northern Cardinal (Cardinalis cardinalis; see Plate 1). Northern Cardinals are yearround resident birds in eastern North America that use a variety of forested, shrubby, and residential habitats. Cardinals exploit a wide variety of natural (e.g., insects and native fruits) and urban-associated food (e.g., birdseed and exotic fruits) and structural resources (e.g., exotic shrubs) that are positively associated with urban development surrounding forest remnants in our Ohio (USA) study system (Leston and Rodewald 2006). Not surprisingly, Cardinal numbers are positively associated with low to moderate amounts of urbanization, and forest remnants within urbanizing landscapes can support 2-4 times the density of Cardinals as can more rural landscapes (Leston 2005, Leston and Rodewald
2006). Cardinals seem to have the capacity to move widely across landscapes to select habitats given that Cardinals are capable of relatively long dispersal movements either as hatch-year birds (e.g., up to $5 \mathrm{~km}$ reported from one study) or adults (e.g., average of 86 $\mathrm{km}$ for male dispersers; Halkin and Linville 1999). Furthermore, previous data from our system also show that individuals regularly move more widely in the landscape during the nonbreeding season, as only one third of color-banded breeding birds were resighted during winter months (Leston 2005). Ongoing research has shown that Cardinals do not experience relaxed predation pressure (Leston and Rodewald 2006) in urban habitats and, to the contrary, nest predation rates are generally higher for Cardinal nests in urban compared to rural forests (A. D. Rodewald, unpublished data). Consequently, bottom-up factors may drive the Cardinal population response to urbanization.

We documented population density, adult body condition, apparent survival, and annual reproductive productivity of Cardinals in riparian forests to examine the extent to which populations reflected (a) resource matching (i.e., fitness parameters of urban and rural birds were equivalent), (b) over-matching of urban habitats (i.e., urban Cardinals exhibit poorer condition, lower survival, and lower reproductive output compared to rural birds), or (c) under-matching of urban habitats (i.e., urban Cardinals have higher fitness and condition measures than do rural birds).

\section{Methods}

Cardinals were studied in 14 riparian forests within and around Columbus, Ohio, USA $\left(\sim 40^{\circ} 00^{\prime} \mathrm{N}, 83^{\circ} 00^{\prime}\right.$ W). Study sites were mature forest corridors $\geq 250 \mathrm{~m}$ long and $>100 \mathrm{~m}$ wide (range: 104-277 m wide) along rivers and were separated from one another by at least 2 $\mathrm{km}$. These riparian forests are similar in shape and landscape configuration; they are narrow, linear, highly connected forests within landscapes dominated by agricultural (e.g., row crop, pasture) and urban (e.g., roads, parking lots, buildings) land cover. One key strength of our study system was that landscapes are similarly fragmented, making it possible to avoid confounding urbanization with habitat loss and fragmentation.

Landscape composition was quantified within 1-kmradius (314-ha) landscapes centered on each site using recent (2002-2004) digital orthophotos and existing data from county auditors. We classified forests as occurring within either "urban" or "rural" landscapes based on landscape-composition metrics as well as the first factor of a principal-components analysis (hereafter "urban index") that explained $>80 \%$ of the landscape variation among sites and loaded strongly on cover types such as roads $(0.940)$, pavement $(0.903)$, lawn $(0.885)$, and agriculture (-0.824). Urban landscapes were defined as those with an urban index $\geq 0$, with $>800$ buildings in the landscape, and bordered by residential developments 
TABLE 1. Land cover characteristics surrounding 14 riparian-forest study sites in rural $(n=6$ sites $)$ and urban $(n=8$ sites) landscapes in central Ohio, USA.

\begin{tabular}{|c|c|c|c|c|c|c|c|c|c|}
\hline \multirow[b]{2}{*}{ Site } & \multirow{2}{*}{$\begin{array}{l}\text { Urban } \\
\text { index }\end{array}$} & \multirow{2}{*}{$\begin{array}{c}\text { No. } \\
\text { buildings } \dagger\end{array}$} & \multirow{2}{*}{$\begin{array}{c}\text { Forest } \\
\text { width }(\mathrm{m})\end{array}$} & \multicolumn{4}{|c|}{ Proportion of 1-km-radius area covered } & \multirow{2}{*}{$\begin{array}{l}\text { Density } \\
\text { (no./2 ha) }\end{array}$} & \multirow{2}{*}{$\begin{array}{l}\text { Territory } \\
\text { size (ha) }\end{array}$} \\
\hline & & & & Agriculture & Lawn & Pavement & Roads & & \\
\hline \multicolumn{10}{|l|}{ Rural } \\
\hline North Galena & -1.27 & 34 & 135 & 0.36 & 0.05 & 0.01 & 0.01 & 1.1 & 1.9 \\
\hline Public hunting & -1.15 & 210 & 194 & 0.32 & 0.08 & 0.01 & 0.01 & 1.6 & 1.2 \\
\hline Prairie Oaks & -1.12 & 58 & 148 & 0.47 & 0.12 & 0.03 & 0.02 & 1.1 & 1.8 \\
\hline Three Creeks & -0.71 & 92 & 133 & 0.10 & 0.10 & 0.04 & 0.02 & 1.1 & 1.9 \\
\hline South Galena & -0.57 & 185 & 163 & 0.14 & 0.30 & 0.02 & 0.01 & 2.0 & 1.0 \\
\hline Galena & -0.48 & 360 & 277 & 0.15 & 0.22 & 0.04 & 0.02 & 1.6 & 1.3 \\
\hline \multicolumn{10}{|l|}{ Urban } \\
\hline Elk Run & -0.16 & 812 & 167 & 0.31 & 0.27 & 0.06 & 0.05 & 3.5 & 0.6 \\
\hline Woodside Green & 0.32 & 1227 & 104 & 0.11 & 0.40 & 0.07 & 0.05 & 1.7 & 1.2 \\
\hline Rush Run & 0.75 & 1611 & 150 & 0 & 0.41 & 0.09 & 0.06 & 4.0 & 0.5 \\
\hline Cherrybottom & 0.76 & 997 & 165 & 0.02 & 0.36 & 0.16 & 0.07 & 2.9 & 0.7 \\
\hline Casto & 1.25 & 1776 & 202 & 0 & 0.42 & 0.20 & 0.08 & 4.3 & 0.5 \\
\hline Lou Berliner & 1.26 & 2272 & 156 & 0 & 0.28 & 0.23 & 0.08 & 4.2 & 0.5 \\
\hline Tuttle & 1.61 & 2285 & 160 & 0 & 0.34 & 0.30 & 0.09 & 3.3 & 0.6 \\
\hline Kenny & 0.89 & 1733 & 126 & 0 & 0.34 & 0.17 & 0.06 & 7.5 & 0.3 \\
\hline
\end{tabular}

Notes: Cardinal densities in 2-ha spot-mapping grids were compiled across 10 annual visits, 2004-2006. Territory size estimates were derived from spot-mapping data.

$\dagger$ Number of buildings per landscape.

and commercial zones (Table 1). Rural landscapes, in contrast, had urban indices of $<0$, contained scattered buildings ( $\leq 360$ structures) within the surrounding landscape, and were bordered by agricultural fields (usually corn or soybean), pastures, or hayfields. One site, Elk Run Park, was considered to occur within an urban landscape despite having an urban index of -0.16 because of the high number of surrounding buildings and its adjacency to residential and commercial developments.

At each study site, a 2-ha grid was established adjacent to the river and marked at 50-m intervals. Grids were generally arranged as $200 \times 100 \mathrm{~m}$ blocks and did not abut forest edges (other than the river), but a few sites required minor deviations (e.g., one 0.5-ha section was shifted to avoid an edge). Spot mapping was used to estimate densities and placement of Cardinal territories within our 2-ha grids in May-July 2004-2006. Two of the sites (Tuttle and Kenny Parks) were added to the study in 2005-2006. Each grid was systematically covered in $\sim 1$-h surveys repeated 10 times per year. All surveys occurred between $15 \mathrm{~min}$ after sunrise and 10:30 hours during mornings without strong wind or precipitation. Numbers and locations of all observed Cardinals were recorded on 2-ha-grid maps.

In order to estimate survival and season-long reproductive success, Cardinals were individually marked with a U.S. Geological Survey aluminum band and a unique combination of three color bands. Immediately upon capture, sex and age of birds were determined, and we measured wing chord length (in $\mathrm{mm}$ ), tarsus length (in $\mathrm{mm}$ ), and mass (in g). Marked individuals were resighted annually by systematically searching the study grid and outlying areas within $300 \mathrm{~m}(>5$ times the width of a Cardinal territory). We also banded and collected morphometric data on 7-9 day-old nestlings from monitored nests.

To estimate annual productivity, field teams monitored all nesting attempts for banded pairs from late March through September, 2003-2006 (2005-2006 for Tuttle and Kenny Parks). Nests were generally located early in the nesting stage (often during building or egglaying). Once located, nests were checked at 1-3 day intervals to determine status (i.e., abandoned, failed, or active). For nests that successfully fledged young, numbers of young were determined by either counting the number of nestlings immediately prior to fledging and/or by observing parents and young for extended periods within 1-2 days of fledging. Individual Cardinals at sites made 1-5 nesting attempts each breeding season. For each breeding pair, all nesting records over the season were compiled to determine the number of nesting attempts and the total number of young fledged over the season.

\section{Data analysis}

Data from spot-mapping grids were averaged over years to produce one density estimate per site. Densities were log-transformed to meet assumptions of normality and analyzed with an analysis of variance. Because Cardinal territories were distributed relatively evenly across sites (i.e., space was fully occupied within the grids), we estimated territory size by dividing the 2-ha grid by the number of pairs.

Maximum-likelihood estimates of apparent annual survival of marked after-hatch-year individuals and detection probabilities were generated using live encounters or recapture models in program MARK (White and Burnham 1999). Separate analyses were run for males $(n=97$ males in urban, $n=50$ males in 
TABLE 2. Morphometric, condition, and survival estimates (mean \pm SE) and $95 \%$ confidence intervals (CI) around survival estimates for Northern Cardinals banded at 14 riparian forest sites in central Ohio, USA, 2003-2006.

\begin{tabular}{|c|c|c|c|c|c|c|}
\hline \multirow[b]{2}{*}{ Variable } & \multicolumn{2}{|c|}{ Male } & \multicolumn{2}{|c|}{ Female } & \multicolumn{2}{|c|}{ Nestlings } \\
\hline & Urban & Rural & Urban & Rural & Urban & Rural \\
\hline Wing length (mm) & $93.8 \pm 0.21$ & $93.7 \pm 0.25$ & $90.7 \pm 0.23$ & $90.7 \pm 0.26$ & $84.0 \pm 0.05$ & $84.0 \pm 0$ \\
\hline Mass $(\mathrm{g})$ & $42.2 \pm 0.19$ & $42.6 \pm 0.25$ & $42.7 \pm 0.34$ & $44.6 \pm 0.38$ & $24.8 \pm 0.36$ & $24.7 \pm 0.50$ \\
\hline Tarsus length (mm) & $24.5 \pm 0.10$ & $24.6 \pm 0.14$ & $23.9 \pm 0.15$ & $24.2 \pm 0.14$ & $23.0 \pm 0.18$ & $22.8 \pm 0.10$ \\
\hline Condition index & $0.2 \pm 0.33$ & $0.3 \pm 0.12$ & $-0.1 \pm 0.67$ & $1.3 \pm 0.41$ & $-0.5 \pm 0.66$ & $0.2 \pm 0.37$ \\
\hline Apparent survival, $\phi$ & $0.67 \pm 0.049$ & $0.58 \pm 0.064$ & $0.53 \pm 0.061$ & $0.63 \pm 0.076$ & & \\
\hline$\phi, 95 \%$ CI & $0.57-0.76$ & $0.46-0.70$ & $0.41-0.64$ & $0.48-0.77$ & & \\
\hline
\end{tabular}

Notes: Morphometric data were collected on 168 males, 142 females, and 118 nestlings. Survival rates were estimated from 147 males and 125 females.

rural) and females $(n=83$ females in urban, $n=42$ females in rural). We used program MARK in an information-theoretic framework to evaluate the relative support for models representing alternative hypotheses driving demographic patterns. Detection probabilities were estimated in MARK as $P=0.91$ (95\% confidence interval: $0.77-0.97)$ for males and $P=0.88$ (95\% confidence interval: $0.65-0.97$ ) for females. Only 5 of 272 individuals were missed in one year and resighted in a subsequent year.

Condition of Northern Cardinals was examined by first applying a principal components analysis to wing and tarsus length. The first principal-component factor explained $72 \%$ of the variation in individual body size (eigenvalue $=1.443$ ). Mass was regressed against this body-size factor separately for 168 males, 142 females, and 118 nestlings. As expected, mass was strongly associated with body size for males $\left(F_{1,166}=4.97, P=\right.$ $0.027)$, females $\left(F_{1,140}=9.45, P=0.003\right)$, and nestlings $\left(F_{1,116}=43.63, P<0.001\right)$. Residuals from models (i.e., whether an individual was below or above its predicted mass given its frame size) were used as a condition index. Residuals were averaged over all individuals at each site and then regressed against the urbanization index.

Numbers of fledglings produced were totaled over all nesting attempts made by 294 known pairs over the entire breeding season. Reproductive productivity was analyzed by first testing for differences in productivity among years with a general linear model. Because annual productivity did not vary significantly among years $\left(F_{1,48}=0.01, P=0.913\right)$, productivity estimates were averaged across years and tested using an analysis of variance with each site treated as a replicate.

\section{RESULTS}

Cardinal densities ranged from 1.1 to $7.5 \mathrm{birds} / 2$-ha grid and log-transformed densities were 4 times higher on urban $(1.3 \pm 0.15$ [mean $\pm \mathrm{SE}])$ compared to rural $(0.31 \pm 0.11)$ forests $\left(F_{1,12}=24.76, P=0.003\right.$; Table 1$)$. Territory sizes were nearly 3 times larger in rural than urban forests $(1.51 \pm 0.16$ ha $[$ mean $\pm \mathrm{SE}$ ] in rural forests vs. $0.6 \pm 0.09$ ha in urban forests; Table 1). Survival rates were similar for birds in urban and rural forests, and the 95\% confidence intervals around survival estimates overlapped (Table 2). Condition indices were not significantly associated with the urban index of sites for males $\left(F_{1,12}=0.19, P=0.672\right)$, females $\left(F_{1,12}=2.58, P=0.134\right)$, or nestlings $\left(F_{1,11}=0.54, P=\right.$ 0.477 ; Table 2 ). Mean annual reproductive productivity per site ranged from 1.5 to 3.1 fledglings per pair, but did not significantly differ between urban $(2.4 \pm 0.18$ young per pair [mean $\pm \mathrm{SE}])$ and rural $(2.1 \pm 0.18$ young per pair) forests $\left(F_{1,12}=1.56, P=0.235\right.$; Fig. 1$)$.

\section{DisCUSSION}

Contrary to recent suggestions that birds may overexploit urban habitats, our findings suggest that high densities of synanthropic species may result from resource matching. Despite maintaining up to 4 times higher population densities in urban than rural landscapes, urban Cardinals exhibited similar rates of survival and reproductive productivity and were in condition similar to that of birds in more rural landscapes. This suggests that higher densities of Cardinals may be a response by individuals to greater resource levels. Indeed, Leston and Rodewald (2006) showed that urban forests contained 2.5 times more fruit, 2.7 times more bird feeders, and 2.5 times more preferred nesting substrate than rural forests. In fact, understory structure best explained variation in Cardinal densities among sites (Leston and Rodewald 2006). Higher levels of resources in urban forests are further supported by the fact that Cardinal territories in urban

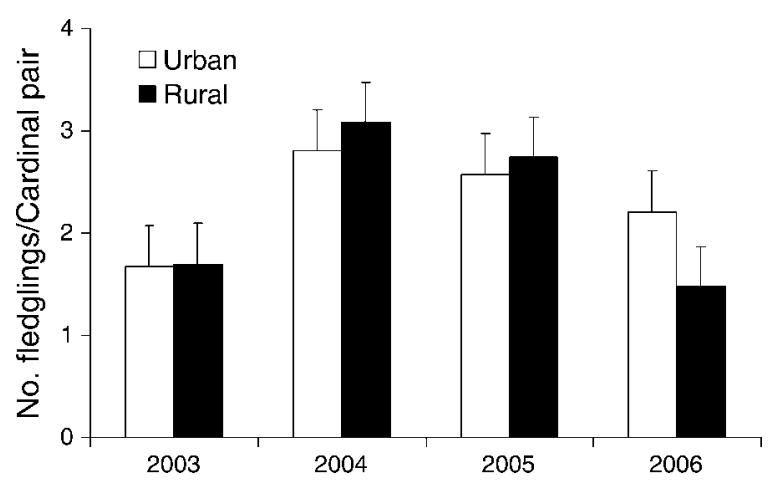

FIG. 1. Number of fledglings produced per pair (mean and SE) at 14 riparian forest sites in central Ohio, USA, 20032006. 
forests were approximately one third the size of those in rural forests, a pattern that matches expectations of decreasing territory size with increasing levels of food resources (Hixon 1980, Smith and Shugart 1987).

Our data support the resource-matching hypothesis to explain the distribution of synanthropic species, where individuals select urban habitats due to greater availability and/or quality of resources. Resource matching has been demonstrated in a wide variety of animals, including fish (Milinski 1984, 1988, Abrahams 1989, Croy and Hughes 1991, Gotceitas and Colgan 1991), beetles (Korona 1990), waterfowl (Harper 1982, Recer et al. 1987), mammals (Morris 1994), and even humans (e.g., whalers; Whitehead and Hope 1991). However, a meta-analysis shows that, as a whole, the distribution of organisms is generally less extreme than the distribution of resources (Kennedy and Gray 1993). Evidence of resource matching by birds is mixed and may vary depending on the stage of the annual cycle. For example, regional distribution of Blackcaps (Sylvia atricpilla), a migratory bird in Europe, during breeding and wintering seasons in Spain was generally consistent with resource matching (Telleria and Perez-Tris 2003). In contrast, use of stopover habitats by migratory passerines reflected under-matching of habitats, perhaps due to imperfect knowledge of resource distribution (Shochat et al. 2002). Birds even may match resource distribution at fine spatial scales, such as microhabitats and foraging substrates, as shown by insectivorous tits (Parus spp.) using different forest strata (Diaz et al. 1998). In our study system, Cardinals may select urban forests for their more abundant nesting substrates (especially exotic honeysuckle, Lonicera maackii) and supplemental food sources, such as birdfeeders (Leston and Rodewald 2006).

Our data do not support an alternative hypothesis that is sometimes invoked to explain high densities of synanthropic species in urban systems: that predation pressure is relaxed in urban areas and this leads to higher survival rates of urban compared to rural birds. Several ecologists have suggested that predation pressure is lower in urban compared to rural or more natural areas (Bowers and Breland 1996, Gering and Blair 1999, Kosinski 2001, Post and Gotmark 2006; but see Jokimaki and Huhta 2000, Thorington and Bowman 2003, Shochat et al. 2004, Jokimaki et al. 2005). However, empirical support is equivocal and often based on indirect measures (e.g., artificial nests, givingup-density experiments). Conceivably urban areas might be associated with lower risk of predation if densities of certain predators were reduced due to sensitivity to humans (Tomialojc 1982, Kosinski 2001, Sorace 2002), if urban predators made different foraging decisions that affected prey preferences (e.g., relying heavily on human-associated food or specializing on certain abundant species; Roth and Lima 2003, Kristan et al. 2004), or perhaps if behavior (e.g., foraging) or habitat use (e.g., nest placement) of prey changed in a way that reduced exposure to predators. There are two important caveats regarding the interpretation of our survival data. First, we do not know survival rates of post-fledging and juvenile birds, and these individuals might face much greater risk of predation than adults, particularly in urban areas with abundant predators. Second, similar rates of survival do not necessarily indicate similar rates of predation because mortality can be attributed to different sources. For example, individuals wintering in rural areas may face higher mortality due to starvation whereas birds in urban areas may be more likely to be depredated, yet both populations could show similar overall survival rates. As a corollary, we suspect that mortality due to winter starvation was not greater in rural compared to urban populations because (a) birds regularly left breeding sites temporarily during winter months, particularly in rural forests where our resighting efforts showed that nearly twice as many individuals left sites in winter compared to urban forests and (b) condition indices were not significantly different between rural and urban populations, though we recognize that mass and fat storage strategies reflect a variety of trade-offs between starvation and predation risk (Houston et al. 1993, Witter and Cuthill 1993, Gosler et al. 1995). Still, if rural birds faced greater mortality due to starvation, one would expect them to be in poorer condition (lower mass for a given frame size).

Despite our inability to identify sources of mortality, several lines of evidence suggest that predation pressure is not relaxed in urban populations in our study system. First, multiple years of survey data show that urban forests have much greater relative abundances of predators, such as corvids, squirrels, and cats, than rural populations (Rodewald, in press). Second, data from a six-year study of nest mortality in Cardinals showed that urban nests faced generally greater risk of predation than nests in rural landscapes (A. D. Rodewald, unpublished data). This increased vulnerability stems, in part, from changes in nest placement induced by exotic shrubs common in urban forests (Borgmann and Rodewald 2004, 2005; Rodewald, in press). Third, the pattern of greater predator abundance coupled with the comparable apparent survival rates make it more likely to find greater risk of predation in urban compared to rural populations, rather than relaxed predation.

Given that rural populations of Cardinals maintained lower densities than urban populations despite similar survival rates of adults and comparable numbers of offspring produced, higher rates of emigration from rural forests presumably contributed to their lower densities. We have some limited evidence to support the idea that rural birds were more likely to emigrate. For example, our efforts to resight color-banded Cardinals during winter months showed that rural forests had nearly twice the amount of dispersal, as only $17 \%$ of rural birds were resighted in winter compared to $31 \%$ of urban birds (Leston 2005). Though some of this 
movement during the nonbreeding season was temporary (some birds returned to the sites to breed in subsequent seasons), it suggests a greater tendency to move off sites in rural landscapes. Furthermore, the only instances in which we resighted banded nestlings in subsequent years occurred in urban landscapes; in both cases young fledged from urban nests and later bred at the natal site.

Although the literature on urban ecology is rich with studies describing correlations between urban land uses and the distribution and abundance of organisms (Beissinger and Osborne 1982, Mills et al. 1989, Blair 1996, Hennings and Edge 2003, Rodewald and Bakermans 2006), few studies investigate how demographic parameters are related to urbanization. Our study is among the first to empirically test predictions of consumer resource-matching in urban systems. Survival, condition, and productivity data over four years provide evidence that high densities of synanthropic species reflect resource matching. These results make an important contribution towards understanding the ecological processes that drive animal responses to urban development.

\section{ACKNOWLEDGMents}

Funding for this research was provided by the National Science Foundation (DEB-0340879 to A. D. Rodewald), Ohio Division of Wildlife, Ohio Agricultural Research and Development Center, and The Ohio State University Swank Program in Rural-Urban Policy. We are grateful to M. H. Bakermans, K. L. Borgmann, F. V. L Leston, J. R. Smith-Castro, and N. Sundell-Turner for their dedicated efforts in the field and laboratory. We thank the following technicians for their help in the field: M. Carll, J. Fullerton, A. Gilmore, B. Graves, J. Gray, S. Hazzard, L. Hitchcock, M. Howie, M. Kanode, J. Kim, S. Landes, T. Magarian, A. Maruster, J. McConnell, D. Miller, J. Morcillo-Blanco, M. Nelson, E. Norris, C. O'Dell, M. Santiago, and A. Vitz. We are grateful to the Franklin County Metro Parks, Columbus Recreation and Parks, Ohio Division of Wildlife, The Nature Conservancy, City of Bexley, Gahanna Parks and Recreation, and private landowners for their cooperation and access to sites. We appreciate the helpful comments from two anonymous reviewers.

\section{Literature Cited}

Abrahams, M. V. 1989. Foraging guppies and the ideal free distribution: the influence of information on patch choice. Ethology 82:116-126.

Atchison, K. A., and A. D. Rodewald. 2006. The value of urban forests to wintering birds. Natural Areas Journal 26: 280-288.

Beissinger, S. R., and D. R. Osborne. 1982. Effects of urbanization on avian community organization. Condor 84 : 75-83.

Blair, R. B. 1996. Land use and avian species diversity along an urban gradient. Ecological Applications 6:506-519.

Borgmann, K. L., and A. D. Rodewald. 2004. Nest predation in urbanizing landscapes: the role of exotic shrubs. Ecological Applications 14:1757-1765.

Borgmann, K. L., and A. D. Rodewald. 2005. Forest restoration in urbanizing landscapes: interactions between land uses and an exotic shrub. Restoration Ecology 13:334-340.

Bowers, M. A., and B. Breland. 1996. Foraging of gray squirrels on an urban-rural gradient: use of the GUD to assess anthropogenic impact. Ecological Applications 6: $1135-1142$.

Croy, M. I., and R. N. Hughes. 1991. Effects of food supply, hunger, danger, and competition on choice of foraging location by the 15 -spined stickleback, Spinachia spinachia L. Animal Behaviour 42:131-139.

Diaz, M., J. C. Illera, and J. C. Atienza. 1998. Food resource matching by foraging tits Parus spp. during spring-summer in a Mediterranean mixed forest; evidence for an ideal free distribution. Ibis 140:654-660.

Faeth, S. H., P. S. Warren, E. Shochat, and W. A. Marussich. 2005. Trophic dynamics in urban communities. BioScience 55:399-407.

Fretwell, D., and H. L. Lucas, Jr. 1969. On territorial behavior and other factors influencing habitat distribution in birds. I. Theoretical development. Acta Biotheoretica 19:16-36.

Gering, J. C., and R. B. Blair. 1999. Predation on artificial bird nests along an urban gradient: Predatory risk or relaxation in urban environments? Ecography 22:532-541.

Gosler, A. G., J. J. D. Greenwood, and C. Perrins. 1995. Predation risk and the cost of being fat. Nature 377:621-623.

Gotceitas, V., and P. Colgan. 1991. Assessment of patch profitability and ideal free distribution - the significance of sampling. Behaviour 119:65-76.

Halkin, S. L., and S. U. Linville. 1999. Northern Cardinal (Cardinalis cardinalis). Pages $1-32$ in A. Poole and F. Gill, editors. The birds of North America, no. 440. The Birds of North America, Philadelphia, Pennsylvania, USA.

Harper, D. G. C. 1982. Competitive foraging in Mallards: "ideal free" ducks. Animal Behaviour 30:575-584.

Hennings, L. A., and W. D. Edge. 2003. Riparian bird community structure in Portland, Oregon: habitat, urbanization, and spatial scale patterns. Condor 105:288-302.

Hixon, M. A. 1980. Food-production and competitor density as the determinants of feeding territory size. American Naturalist 115:510-530.

Houston, A. I., J. M. McNamara, and J. M. C. Hutchinson. 1993. General results concerning the trade-off between gaining energy and avoiding predation. Philosophical Transactions of the Royal Society of London B 341:375-397.

Jokimaki, J., and E. Huhta. 2000. Artificial nest predation and abundance of birds along an urban gradient. Condor 102: 838-847.

Jokimaki, J., M. L. Kaisanlahti-Jokimaki, A. Sorace, E. Fernandez-Juricic, I. Rodriguez-Prieto, and M. D. Jimenez. 2005. Evaluation of the "safe nesting zone" hypothesis across an urban gradient: a multi-scale study. Ecography 28:59-70.

Kennedy, M., and R. D. Gray. 1993. Can ecological theory predict the distribution of foraging animals? A critical analysis of experiments on the ideal free distribution. Oikos 68:158-166.

Korona, R. 1990. Travel costs and ideal free distribution of ovipositing female flour beetles, Tribolium confusum. Animal Behaviour 40:186-187.

Kosinski, Z. 2001. Effects of urbanization on nest site selection and nesting success of the Greenfinch Carduelis chloris in Krotoszyn, Poland. Ornis Fennica 78:175-183.

Kristan, W. B., W. I. Boarman, and J. J. Crayon. 2004. Diet composition of common ravens across the urban-wildland interface of the West Mojave Desert. Wildlife Society Bulletin 32:244-253.

Leston, L. F. V. 2005. Are urban riparian forests ecological traps for understory birds? Habitat selection by Northern Cardinals (Cardinalis cardinalis) in urbanizing landscapes. Ohio State University, Columbus, Ohio, USA.

Leston, L. F. V., and A. D. Rodewald. 2006. Are urban forests ecological traps for understory birds? An examination using Northern Cardinals. Biological Conservation 131:566-574.

Marzluff, J. M., R. Bowman, and R. E. Donnelly. 2001. Avian ecology and conservation in an urbanizing world. Kluwer Academic Publishers, Norwell, Massachusetts, USA. 
Milinski, M. 1984. Competitive resource sharing: an experimental test of a learning rule for ESSs. Animal Behaviour 32: 233-242.

Milinski, M. 1988. Games fish play: making decisions as a social forager. Trends in Ecology and Evolution 3:325-330.

Mills, G. S., J. B. Dunning, and J. M. Bates. 1989. Effects of urbanization on breeding bird community structure in Southwestern desert habitats. Condor 91:416-428.

Morris, D. W. 1994. Habitat matching: alternatives and implications to populations and communities. Evolutionary Ecology 8:387-406.

Parker, G. E. 1978. Searching for mates. Pages 214-244 in J. R. Krebs and N. B. Davies, editors. Behavioral ecology: an evolutionary approach. Sinauer, Sunderland, Massachusetts, USA.

Post, P., and F. Gotmark. 2006. Seasonal changes in Sparrowhawk Accipiter nisus predation: prey vulnerability in relation to visibility in hunting habitats and prey behaviour. Ardea 94:77-86.

Pulliam, R. H., and T. Caraco. 1984. Living in groups: is there an optimal group size? Pages 122-147 in J. R. Krebs and N. B. Davies, editors. Behavioral ecology: an evolutionary approach. Blackwell Scientific, Oxford, UK.

Recer, G. M., W. U. Blanckenhorn, J. A. Newman, E. M. Tuttle, M. L. Withiam, and T. Caraco. 1987. Temporal resource variability and the habitat-matching rule. Evolutionary Ecology 1:363-378.

Rodewald, A. D. In press. Evaluating potential factors that guide avian community response to urbanization. Studies in Avian Biology.

Rodewald, A. D., and M. H. Bakermans. 2006. What is the appropriate paradigm for riparian forest conservation? Biological Conservation 128:193-200.

Roth, T. C., and S. L. Lima. 2003. Hunting behavior and diet of Cooper's Hawks: an urban view of the small-bird-in-winter paradigm. Condor 105:474-483.

Shochat, E. 2004. Credit or debit? Resource input changes population dynamics of city-slicker birds. Oikos 106:622626.
Shochat, E., Z. Abramsky, B. Pinshow, and M. Whitehouse. 2002. Density-dependent habitat selection in migratory passerines during stopover: What causes the deviation from IFD? Evolutionary Ecology 16:469-488.

Shochat, E., S. B. Lerman, M. Katti, and D. B. Lewis. 2004. Linking optimal foraging behavior to bird community structure in an urban-desert landscape: field experiments with artificial food patches. American Naturalist 164:232243.

Shochat, E., P. S. Warren, S. H. Faeth, N. E. McIntyre, and D. Hope. 2006. From patterns to emerging processes in mechanistic urban ecology. Trends in Ecology and Evolution 21:186-191.

Smith, T. M., and H. H. Shugart. 1987. Territory size variation in the Ovenbird: the role of habitat structure. Ecology 68: 695-704.

Sorace, A. 2002. High density of bird and pest species in urban habitats and the role of predator abundance. Ornis Fennica 79:60-71.

Telleria, J. L., and J. Perez-Tris. 2003. Seasonal distribution of a migratory bird: effects of local and regional resource tracking. Journal of Biogeography 30:1583-1591.

Thorington, K. K., and R. Bowman. 2003. Predation rate on artificial nests increases with human housing density in suburban habitats. Ecography 26:188-196.

Tomialojc, L. 1982. Synurbanization of birds and preypredators relations. Pages $131-137$ in M. Luniak and B. Pisarski, editors. Animals in urban environments. Ossolineum, Wroclaw, Poland.

White, G. C., and K. P. Burnham. 1999. Program MARK: survival estimation from populations of marked animals. Bird Study 46(Supplement):120-138.

Whitehead, H., and P. L. Hope. 1991. Sperm whalers off the Galapagos Islands and in the western North Pacific, 1830 1850. Ideal free whalers. Ethology and Sociobiology 12:147161.

Witter, M. S., and I. C. Cuthill. 1993. The ecological costs of avian fat storage. Philosophical Transactions of the Royal Society of London B 340:73-92. 